\title{
Primary Hyperoxaluria is the Main Cause of Chronic Renal Failure in Children under 15 Years Old in Jenin District (Palestine)
}

Jamal Qasem Abumwais*

Ministry of Education and Higher Education, Palestine

\begin{abstract}
Background: This was the first study which has been conducted on chronic renal failure children under 15 years old in Jenin District to know the underlying etiology of the disease. The study was conducted on all patients who are treated by medications or hemodialysis in the dialysis unit of The Martyr Dr. Khalil Sulaiman Hospital in Jenin city which is the only dialysis unit in Jenin District where all the patients in Jenin District are treated. The study was conducted in the period $1 / 8 / 2005$ to $1 / 8 / 2006$

Materials and methods: The subjects were nine patients. The information was taken from files of the patients in the kidney unit. The diagnosis was based on family history, medical history, laboratory tests, X-rays, CT scans, ultrasound and renal biopsies.

Results: The results showed that the causes of chronic renal failure were primary hyperoxaluria $(66.7 \%)$ and congenital abnormalities of the kidney (33.3\%).

Conclusion: It is obvious from the results that the most common cause of CRF in children under 15 years old in Jenin District was primary hyperoxaluria which is an inherited disorder. These results differ from what is found in many countries around the world including Arab and Islamic countries where the most common causes of chronic renal failure in children are urological abnormalities and malformations (congenital anomalies) and not primary hyperoxaluria. The primary inherited nephropathy in Jenin District was primary hyperoxaluria with a percentage much higher than that found in many countries around the world. This seems to be due to the very high prevalence of parental consanguinity (especially among cousins) in some families in Jenin District, a practice that is repeated through generations.
\end{abstract}

Keywords: Congenital anomalies; Consanguineous marriage; Jenin district; Palestine; Primary hyperoxaluria; Renal failure

\section{Introduction}

Chronic renal failure (CRF) implies long-standing, and usually progressive, impairment in renal function [1]. CRF is a pathophysiologic process with multiple etiologies, resulting in the inexorable attrition of nephron number and function and frequently leading to end-stage renal disease (ESRD). In turn, ESRD represents a clinical state or condition in which there has been an irreversible loss of endogenous renal function, of a degree sufficient to render the patient permanently dependent upon renal replacement therapy (dialysis or transplantation) in order to avoid life-threatening uremia [2].

Causes of chronic renal failure differ according to age of the person. Renal failure in the elderly more often results from renal vascular disease or urinary tract obstruction than in younger age groups [1]. In addition to difference in causes of CRF between young and aged persons, the incidence and etiology of CRF in children vary according to age of the child, ethnic origin, and in different parts of the world which may be caused by differences in pediatric services [3].

Primary hyperoxaluria is a rare hereditary disorder that leads to chronic renal failure, for example, among children in the developed world it is a very rare disorder accounts for 1\% of ESRD in Europe and $0.2 \%$ in USA [4]. Data from the Arab world show that the prevalence of primary hyperoxaluria among children is much higher as reported in Tunisia (13 \%) [4] and Kuwait (10.4\%) [5].

Increasing cases of primary hyperoxaluria have been noticed in the last few years in one family in Jenin District especially among young children, so I aimed in this study to know the underlying etiology of chronic renal failure in children under 15 years old in Jenin District, and to know if primary hyperoxaluria is a major or minor cause of chronic renal failure among children in Jenin district.

\section{Materials and Methods}

Area of study

This study included Jenin District which includes Jenin city and the surrounding villages with a population of about 280000 persons.

\section{Study subjects}

This study was conducted on all chronic renal failure patients under the age of 15 years who are treated by medications or hemodialysis in The Martyr Dr. Khalil Sulaiman Hospital in Jenin city in the period $1 / 8 / 2005-1 / 8 / 2006$.

\section{Study period}

The study continued for one year (1/8/2005 - 1/8/2006).

\section{Setting of the study}

The study has been conducted at the laboratory and kidney unit of The Martyr Dr. Khalil Sulaiman Hospital in Jenin city which is the only kidney unit in Jenin District were all patients from Jenin district are treated.

\section{Aim of the study}

The aim of the study was to know the underlying etiology of CRF in children of less than 15 years old in Jenin District.

*Corresponding author: Jamal Qasem Abumwais, Ministry of Education and Higher Education - Palestine, Tel: 0097242518312, 00972599072538 E-mail: jamal_abumwais@yahoo.com

Received March 19, 2013; Accepted April 15, 2013; Published April 20, 2013

Citation: Abumwais JQ (2013) Primary Hyperoxaluria is the Main Cause of Chronic Renal Failure in Children under 15 Years Old in Jenin District (Palestine). Hereditary Genetics S1: 005. doi:10.4172/2161-1041.S1-005

Copyright: (C 2013 Abumwais JQ. This is an open-access article distributed under the terms of the Creative Commons Attribution License, which permits unrestricted use, distribution, and reproduction in any medium, provided the original author and source are credited. 
Citation: Abumwais JQ (2013) Primary Hyperoxaluria is the Main Cause of Chronic Renal Failure in Children under 15 Years Old in Jenin District (Palestine). Hereditary Genetics S1: 005. doi:10.4172/2161-1041.S1-005

\section{Information about underlying etiology of chronic renal failure}

The information was obtained from files of the patients in the kidney unit. The diagnosis was based on family history, medical history, laboratory tests, X-rays, ultrasound, CT scans and renal biopsies.

Concerning the patients of congenital anomalies, the diagnosis was based mainly on kidney and urinary tract ultrasound.

Patients of primary hyperoxaluria were diagnosed depending on medical history, family history, urine analysis, X-rays, kidney ultrasound, CT scans, and kidney biopsy. Family history revealed that all the patients of primary hyperoxaluria belong to a tribe with a history of primary hyperoxaluria, all the patients had relatives (some are firstdegree relatives) who were diagnosed with primary hyperoxaluria, some of them died and some are still alive. Urine analysis showed marked calcium oxalate crystals in all the patients. X-rays, CT scans and kidneys ultrasound showed multi stones or calcium oxalate deposits in both kidneys of all the patients. Kidney biopsies were done for two patients (whose ages are 6.5 years, 6.5 years respectively). Renal biopsies showed extensive calcium oxalate crystals deposition in both kidneys.

\section{Statistical Analysis}

Mean and standard deviation were used to analyze the results of this study.

\section{Results}

Until the end of the study period, nine patients were diagnosed with chronic renal failure. The subjects were 2 males and 7 females. The female to male ratio was 3.5. The age of the patients and the underlying etiology are listed in table 1.
The mean age of all the patients was 5.48 with a standard deviation of \pm 5.64 years $(5.48 \pm 5.64)$, on the other hand, the mean age of primary hyperoxaluria patients was $3.305 \pm 2.76$ years while the mean age of patients with kidney abnormalities was $9.83 \pm 8.09$ years.

It was found that the causes of chronic renal failure in children less than 15 years old in Jenin District were primary hyperoxaluria (66.7\%) and congenital anomalies (33.3\%) showing the ability of these disorders to induce chronic renal failure at an early age. The age intervals of the patients for each etiology are summarized in table 2.

The results showed that consanguineous marriage - especially among cousins - increase the incidence of primary hyperoxaluria, the degree of relativity between parents of the patients are listed in table 3 .

The results also showed that seven patients were treated conservatively and two patients were treated by hemodialysis. Of the seven patients who were treated conservatively, six were patients of hyperoxaluria and one patient with congenital abnormality. The other two patients with congenital abnormalities were treated by hemodialysis.

Regarding the outcome of the patients at the end of the study period, the results showed that two of the nine patients died during the study period (annual mortality rate $=22.2 \%$ ). One of the dead patients was a patient of congenital abnormality (congenital small kidneys) , he was an infant of about six months and died before beginning of hemodialysis, giving a mortality rate among patients of congenital anomalies of $33.3 \%$. The other dead patient was also an infant of about seven months suffering from severe hyperoxaluria giving a mortality rate among patients of hyperoxaluria of $16.7 \%$.

\begin{tabular}{|c|c|c|c|c|}
\hline Patient number & $\begin{array}{c}\text { Age of the } \\
\text { patient (years) }\end{array}$ & Cause of chronic renal failure & $\begin{array}{l}\text { Family history of primary } \\
\text { hyperoxaluria }\end{array}$ & Way of diagnosis \\
\hline 1 & $7 / 12$ (0.58 year) & Primary hyperoxaluria & uncle & $\begin{array}{l}\text { medical history, family history, X-ray, kidney } \\
\text { ultrasound, CT scan, urine analysis }\end{array}$ \\
\hline 2 & $9 / 12$ ( 0.75 year $)$ & Primary hyperoxaluria & $\begin{array}{l}\text { sister, } 2 \text { uncles (one related to } \\
\text { mother, the other related to father) }\end{array}$ & $\begin{array}{l}\text { medical history, family history, X-ray, kidney } \\
\text { ultrasound, CT scan, urine analysis }\end{array}$ \\
\hline 3 & 1.5 & Primary hyperoxaluria & brother & $\begin{array}{l}\text { medical history, family history, X-ray, kidney } \\
\text { ultrasound, CT scan, urine analysis }\end{array}$ \\
\hline 4 & 4 & Primary hyperoxaluria & $\begin{array}{l}\text { sister, } 2 \text { uncles (one related to } \\
\text { mother, the other related to father) }\end{array}$ & $\begin{array}{l}\text { medical history, family history, X-ray, kidney } \\
\text { ultrasound, CT scan, urine analysis }\end{array}$ \\
\hline 5 & 6.5 & Primary hyperoxaluria & $\begin{array}{l}\text { sister, } 2 \text { uncles ( one related to } \\
\text { mother, the other related to father) }\end{array}$ & $\begin{array}{l}\text { medical history, family history, X-ray, kidney ultrasound, } \\
\text { CT scan, urine analysis, and kidney biopsy }\end{array}$ \\
\hline 6 & 6.5 & Primary hyperoxaluria & uncle & $\begin{array}{l}\text { medical history, family history, X-ray, kidney ultrasound, } \\
\text { CT scan, urine analysis, and kidney biopsy }\end{array}$ \\
\hline 7 & 0.5 & congenital abnormalities of the kidneys & - & kidneys and urinary tract ultrasound \\
\hline 8 & 14 & congenital abnormalities of the kidneys & - & kidneys and urinary tract ultrasound \\
\hline 9 & 15 & congenital abnormalities of the kidneys & - & kidneys and urinary tract ultrasound \\
\hline
\end{tabular}

Table 1: Age of the patients and cause of chronic renal failure in children less than 15 years old in Jenin District.

\begin{tabular}{|c|c|c|c|c|}
\hline \multirow{2}{*}{ Etiology of C.R.F } & Number of patients & Percentage & \multicolumn{2}{|c|}{ Age intervals of the patients ( years) } \\
\cline { 3 - 5 } & 6 & $66.7 \%$ & 2 & $1-5$ \\
\hline${ }^{*}$ Primary hyperoxaluria & 3 & $33.3 \%$ & 1 & 2 \\
\hline${ }^{*}$ Congenital anomalies & 6 & 2 & - \\
\hline
\end{tabular}

Table 2: The etiology and age intervals of the nine CRF patients less than 15 years old in Jenin District.

\begin{tabular}{|c|c|c|c|c|c|c|}
\hline \multirow{2}{*}{ Etiology of CRF } & \multicolumn{2}{|c|}{ Parents are cousins } & \multicolumn{2}{|c|}{ Parents are from the same family } & \multicolumn{2}{|c|}{ Parents are from different families } \\
\hline & Number of patients & Percentage & Number of patients & Percentage & Number of patients & Percentage \\
\hline${ }^{*}$ Congenital anomalies of the kidney & 1 & $33.33 \%$ & 1 & $33.33 \%$ & 1 & $33.33 \%$ \\
\hline *Primary hyperoxaluria & 6 & $100 \%$ & - & - & - & - \\
\hline
\end{tabular}

Table 3: The degree of relativity between parents of CRF patients under 15 years old in Jenin District (Palestine). 


\section{Discussion}

It is obvious from the results that the most common cause of CRF in children of $<15$ years old in Jenin District was primary hyperoxaluria. This is not in line with what is found in many countries around the world including Arab and Islamic countries in the middle east where the most common causes of chronic renal failure in children are urological abnormalities and malformations (congenital anomalies) and not primary hyperoxaluria as reported in Qatar [6]; Turkey [7]; Iran [8]; Jordan [9]; Kuwait [10]; India [11]; Iraq [12]; Italkid project [13]; Saudi Arabia [14].

The percentage of Primary hyperoxaluria among children in Jenin District is much higher than that found in many countries around the world including Arab and Islamic countries as reported in Tunisia [4]; Kuwait [5]; and Iran [8]. This may be due to the very high prevalence of parental consanguinity in Jenin District compared to these countries. Parental consanguinity (especially among cousins) is a very common practice in some families who live in Jenin District particularly some families who live in villages.

According to our results, parents of all the patients of primary hyperoxaluria were cousins (Parental consanguinity is 100\%). Three of the patients were sisters. In addition, all the patients of primary hyperoxaluria were from one family which consists of about 800 persons and live in a small village called Almoghaeir. Consanguineous marriage especially among cousins is a very common practice in this family and is repeated through generations (Ghalib Abumwais: personal communications). Consanguineous marriage is present also among parents of $66.66 \%$ of the patients with congenital anomalies. One of the patients with congenital anomalies was also from the former family and was suffering from congenital small kidneys, he also had a brother suffering from primary hyperoxaluria, so consanguineous marriage not only increase the incidence of inherited kidney diseases as primary hyperoxaluria but also the incidence of congenital abnormalities.

From reviewing the files of all chronic renal failure patients in Jenin District present in the kidney unit of Jenin District during the same period, it was concluded that primary hyperoxaluria is not only the main cause of chronic renal failure among children, but it is the primary inherited nephropathy in Jenin District in all ages accounting for $10.71 \%$ of all chronic renal failure cases, a percentage which is higher than that of Alport's syndrome (5.95\%) and polycystic kidney disease (1.19\%) which are the two most common inherited nephropathies worldwide [15].

The results showed that both primary hyperoxaluria and congenital malformations of the kidney may cause severe uremia and lead to end-stage renal at an early age after birth (infants). These patients usually have bad prognosis, they need to be treated by hemodialysis or transplantation which are very complicated procedures for infants and are unavailable in Palestine, so they usually die from severe uremia.

\section{Conclusion}

The main cause of chronic renal failure in children $<15$ years old in Jenin District is primary hyperoxaluria (66.7\%) which is an inherited disorder. The other causes are congenital anomalies or malformations which accounts for $(33.3 \%)$ of cases. This is different from what was found in many countries around the word including many Arab and Islamic countries where the most common causes of chronic renal failure in children are urological abnormalities and malformations (congenital anomalies) and not primary hyperoxaluria as reported in Qatar, Turkey, Iran, Jordan, Kuwait, India, Iraq, Italkid project, Saudi Arabia. It was concluded also that primary hyperoxaluria is the primary inherited nephropathy in Jenin District in all age's forms $10.71 \%$ of all chronic renal failure cases which is higher than that for Alport's syndrome (5.95\%) and polycystic kidney disease (1.19\%). The high prevalence of primary hyperoxaluria in Jenin District compared to many foreign, Islamic or even Arab countries is primarily due to the very common practice of consanguineous marriage - especially among cousins - in some families in Jenin District. Consanguineous marriage may be also responsible about the high prevalence of congenital malformations. It was also concluded that primary hyperoxaluria and congenital small kidneys may cause severe uremia and lead to end-stage renal disease few months after birth, which is a serious problem and difficult to treat, so this finally leads to death.

\section{Acknowledgements}

I am greatly indebted to Palestinian Ministry of Health and to Dr. Mohammad Abu-Ghali, the head master of The Martyr Dr. Khalil Sulaiman Hospital who gave me the chance to do this study. Special thanks to all the physicians and nurse staff in the kidney unit especially Khalid sobh for their support. I would not forget to thank the children who participated in the study and their parents.

\section{References}

1. Yaqoob M (2005) Renal disease. Clinical Medicine. (6thedn). Elsevier Saunders. USA.

2. Shorecki K, Green J, Brenner BM (2005) Chronic renal failure. (16thedn). Harrison's Principles of Internal Medicine. McGraw Hill Companies Inc.USA.

3. El Aun M, Hazza I, Qudah E, Najada AH, Khairi Y (1995) Causes of chronic renal failure in children in a single hospital in jordan: a 10 years retrospective study. Saudi J Kidney Dis Transpl 6: 290-293.

4. Kamoun A (1997) Spectrum of pediatric renal diseases in Tunisia. Saudi $J$ Kidney Dis Transpl 8: 317-319.

5. Al-Eisa AA, Samhan M, Naseef M (2004) End-stage renal disease in Kuwaiti children: an 8-year experience. Transplant Proc 36: 1788-1791.

6. AkI KF (1995) Childhood chronic renal failure in qatar. Saudi J Kidney Dis Transpl 6: 418-419.

7. Sirin A, Emre S, Alpay H, Nayir A, Bilge I, et al. (1995) Etiology of chronic rena failure in Turkish children. Pediatr Nephrol 9: 549-552.

8. Madani K, Otoukesh H, Rastegar A, Van Why S (2001) Chronic renal failure in Iranian children. Pediatr Nephrol 16: 140-144.

9. Hamed RM (2002) The spectrum of chronic renal failure among Jordanian children. J Nephrol 15: 130-135

10. Al-Eisa A, Naseef M, Al-Hamad N, Pinto R, Al-Shimeri N, et al. (2005) Chronic renal failure in Kuwaiti children: an eight-year experience. Pediatr Nephrol 20 1781-1785.

11. Hari P, Singla IK, Mantan M, Kanitkar M, Batra B, et al. (2003) Chronic renal failure in children. Indian Pediatr 40: 1035-1042.

12. Al-Mosawi AJ (2002) The etiology of chronic renal failure in 54 Iraqi children. Pediatr Nephrol 17: 463-464

13. Ardissino G, Daccò V, Testa S, Bonaudo R, Claris-Appiani A, et al. (2003) Epidemiology of chronic renal failure in children: data from the ItalKid project. Pediatrics 111: e382-387.

14. Kari JA (2006) Chronic renal failure in children in the Western area of saudi arabia. Saudi J Kidney Dis Transpl 17: 19-24.

15. Grunfeld JP (1997) Hereditary renal diseases. Saudi J Kidney Dis Transpl 8 : 227-234.

This article was originally published in a special issue, Hereditary Disorder handled by Editor(s). Dr. X. Long Zheng, University of Pennsylvania, USA 